\title{
Necrotising fasciitis caused by Vibrio vulnificus
}

\author{
ML WOO,* WGD PATRICK, MTP SIMON, † GL FRENCH* \\ From the *Chinese University of Hong Kong, Shatin, Hong Kong, and the †United Christian Hospital, Kwun \\ Tong, Hong Kong
}

SUMMARY A case of necrotising fasciitis caused by Vibrio vulnificus is described. The need for early recognition and aggressive surgical treatment are highlighted, and the necrotising infections due to $V$ vulnificus described in the published work are reviewed.

Necrotising fasciitis is a rapidly progressing necrotising process involving subcutaneous tissue and fascia but sparing muscles, and is accompanied by severe systemic toxicity. ${ }^{2}$ The syndrome is often caused by group A streptococci, ${ }^{13}$ but it is now recognised that other bacteria may be involved, usually in mixed culture. Organisms that have been implicated include a variety of anaerobes, enterobacteria, non-group A streptococci, pseudomonas, and staphylococcus. ${ }^{45}$ Vibrio vulnificus is a recently described halophilic vibrio which causes necrotic skin lesions following wound infection. ${ }^{6}$ We have recently seen a child who presented with classic necrotising fasciitis caused by $V$ vulnificus alone.

\section{Case report}

An 8 year old schoolboy was admitted with a high fever $\left(40.2^{\circ} \mathrm{C}\right)$, chills and rigors, and a peripheral white cell count of $19 \times 10^{9} / 1$. On the day before admission he had suffered a small abrasion over his left thigh, which he rubbed with dirty water from a basin. On admission, he was toxic and lethargic. His left thigh was swollen and extremely tender and showed several black blisters (about 1-2 cm in diameter) delimited by necrotic purple-blue skin. His condition deteriorated rapidly despite antibiotic treatment. On the next day he went into septicaemic shock, but he was resuscitated successfully. The skin over the left thigh and upper leg became dusky with bullous formation. The margin of the lesion progressed rapidly, spreading up to the left groin and down to the lower calf (Figs. 1 and 2). Discoloration of the left lower quadrant of the abdominal wall was also noticed on the third day.

Sixty two hours after admission necrotising fasciitis was diagnosed and an emergency radical

Accepted for publication 24 July 1984 debridement was performed under general anaesthesia. Necrotising fasciitis was confirmed at operation. There was extensive necrosis of the skin, subcutaneous tissue, and the deep fascia, but muscle was spared. Vessels in the subcutaneous tissue were thrombosed, and tissue necrosis was more widespread than the skin lesions had suggested. The patient improved almost immediately after the operation. The wound required skin grafting, but was completely healed after two months.

\section{MICROBIOLOGY}

Cultures of blood and debrided tissue yielded a pure growth of an aerobic, halophilic, oxidase positive, Gram negative bacterium with the characteristics of $V$ vulnificus. This strain was sensitive to ampicillin, chloramphenicol, co-trimoxazole, gentamicin, and amikacin, but resistant to cephalothin. The identification was confirmed by Dr JV Lee of the Public Health Laboratory Service, Centre for Applied Microbiology and Research, Porton Down, Salisbury, UK.

\section{HISTOPATHOLOGY}

Histology of debrided tissue showed focal necrosis in the skin and subcutaneous tissue with subepidermal bulla formation. There was diffuse infiltration with polymorphonuclear and mononuclear inflammatory cells. The subcutaneous vasculature was congested. Numerous Gram negative vibrios were seen in necrotic areas and spreading along the deep fascia. Careful search failed to find any other organism.

This strain of $V$ vulnificus was used in the animal model of Poole and Oliver.' The $\mathrm{LD}_{\mathrm{so}}$ was about $7 \times 10^{3}$ colony forming units. This dose produced necrotic skin lesions in survivors when given to ICR adult mice by intradermal and subcutaneous injection, while control injections of the same dose of 


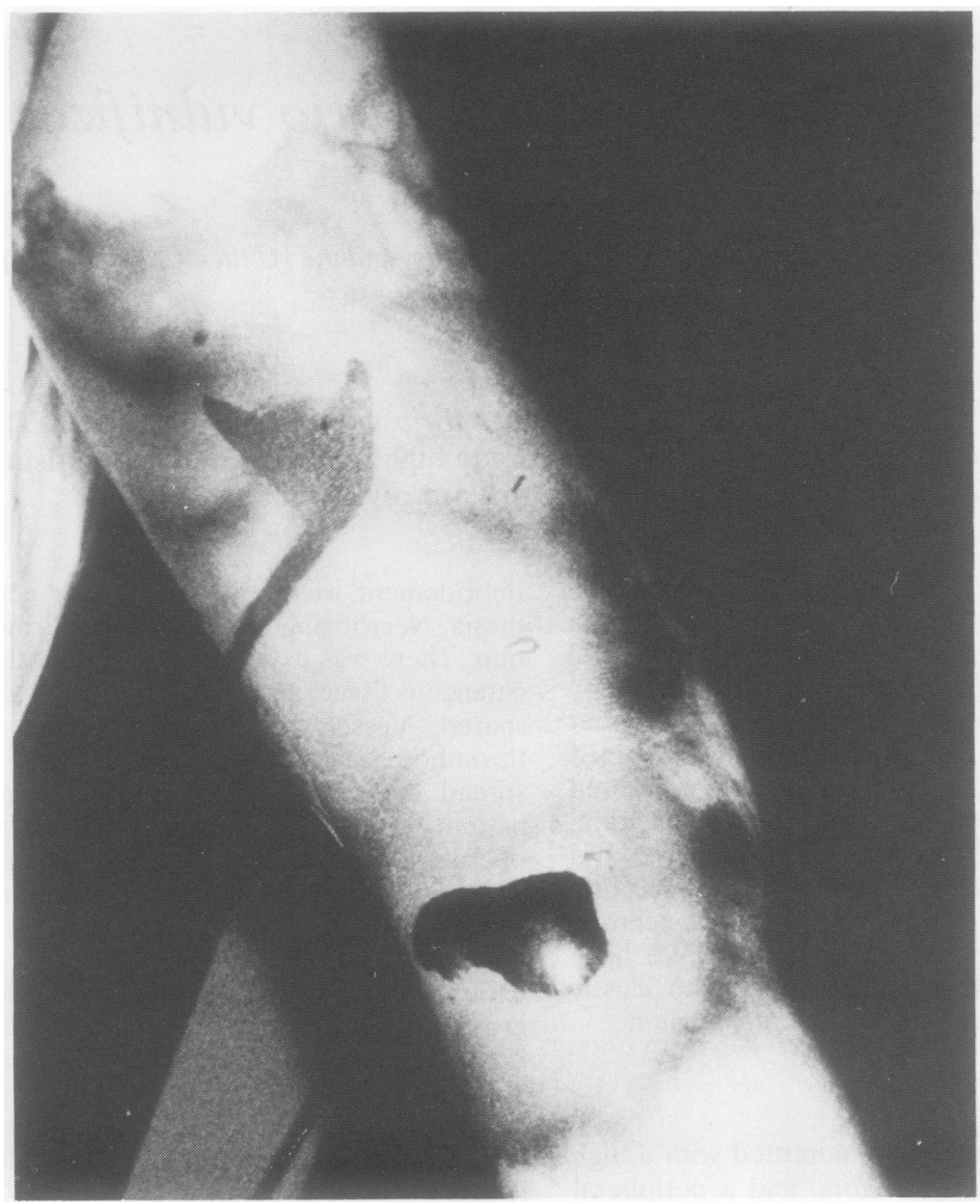

Figs. 1 and 2 Skin lesions of the left leg.

$V$ parahaemolyticus did not. Tissue sections of the experimental lesions showed typical appearances of necrotising fasciitis, with extensive necrosis of dermal tissues and numerous polymorphonuclear leucocytes and vibrios spreading along fascial planes. Muscle tissue was much less affected than the dermis, but it too showed some necrotic changes.

\section{Discussion}

There is no doubt that in this patient necrotising fasciitis was caused by $V$ vulnificus alone. The patient had all the classic clinical, anatomical, and histological features of the disease: the organism was isolated in pure culture from both blood and tissue taken at different times; the isolated strain produced a similar syndrome when injected into mice; and the organism with its characteristic appearance was seen in tissue sections of lesions from both the patient and experimentally infected animals.

Giuliano et $a^{5}$ suggested that streptococci are the most common single bacterial cause of necrotising fasciitis, and non-group A streptococci with $\mathrm{Bac}$ teroides fragilis is the most common combination. Numerous other bacteria have also been implicated, including peptostreptococci, peptococci, clostridia, other bacteroides species, fusobacteria, Staphylococcus aureus, Escherichia coli, citrobacter, klebsiella, enterobacter, serratia, Proteus mirabilis and Pseudomonas aeruginosa. ${ }^{5} V$ vulnificus has not previously been given as a cause of necrotising fasciitis, but there are a large number of reports noting necrotic skin lesions associated with Vibrio vulnificus (or "lactose-positive halophilic vibrio" ${ }^{8}$ ) wound infection and septicaemia. 


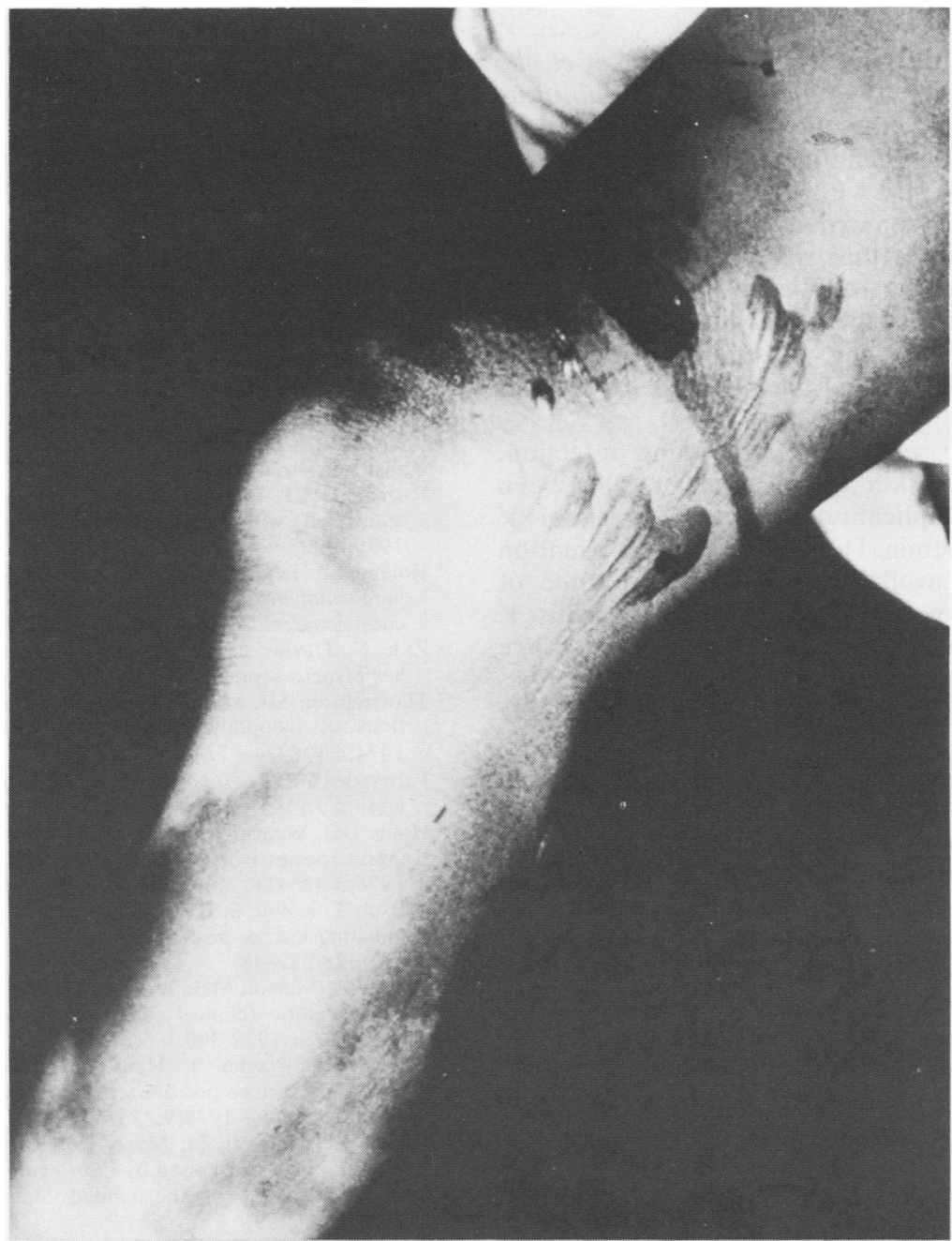

Fig. 2

Roland ${ }^{10}$ reported a case of gangrene of the leg with massive necrosis of adipose and muscular tissue after sea bathing and "clamming." "Vibrio parahaemolyticus" was isolated from the exudate of the leg $^{10}$ but was later identified as a lactose fermenting halophilic vibrio. ${ }^{8}$ A case of erythema multiforme with fatal fulminating septicaemia was described by Zide." Blood culture yielded "Vibrio parahaemolyticus," which was later identified as a lactose fermenting halophilic vibrio. ${ }^{8}$ Microscopical examination of the skin lesions showed focal acute fat necrosis in subcutaneous tissues, and the dermis was infiltrated by Gram negative bacteria. Thorsteinson et $a l^{12}$ reported three cases of halophilic noncholera vibrio infection. One of the patients had a non-purulent thumb infection that required fasciotomy and another had gangrene of the leg and died despite amputation. Fernandez and Pankey ${ }^{13}$ described three cases of severe necrotising cellulitis, two of which yielded a lactose positive, halophilic vibrio. Five patients with septicaemia and wound infections caused by a similar organism were described by Hollis et al.$^{14}$ All five died shortly after admission, but details of the skin lesions were not given. Matsuo et al $^{15}$ described a fatal case of septicaemia caused by a lactose positive halophilic vibrio, presenting with bullae on the legs and eruptions over the arms. Histological examination of the skin lesions showed areas of fibroadipose necrosis in the dermis and subcutaneous tissue. Massive bacterial 
infiltration in the skin was also noted.

Blake et al, ${ }^{16}$ Mertens $e t$ al, ${ }^{17}$ and Tacket et al ${ }^{18}$ reported altogether 18 patients with $V$ vulnificus wound infections, the lesions being variously described as bullous, cellulitic, or necrotic. Castillo ${ }^{19}$ described two patients with $V$ vulnificus septicaemia who developed haemorrhagic and necrotic skin lesions of the hands that required urgent surgical debridement. Finally, Kelly $e t a^{20}$ reported a fatal case of $V$ vulnificus septicaemia with acute necrotising myositis of the leg. Postmortem dissection showed focal necrosis and haemorrhage of the calf muscles. ${ }^{17}$

In all these cases of serious wound infection, spreading necrotic skin lesions appear to have been regarded as complications of an often fatal $V$ vulnificus septicaemia. Detailed clinical information was not always available, however, and some of these patients may have had necrotising fasciitis. $V$ vulnificus necrotising fasciitis may be part of a range of conditions, varying from localised focal necrosis of the dermis to widespread skin and muscle necrosis.

Wound infections due to $V$ vulnificus are usually caused by contamination with sea water or sea food. ${ }^{6}$ In our case there was no history of such exposure. The domestic water supply was cultured but no pathogen was isolated, and the basin of dirty water which the patient used to rub the abrasion had been poured away.

Although caused by an unusual organism, this case of necrotising fasciitis illustrates the general principles of management of this condition, including early recognition and immediate aggressive surgical treatment. ${ }^{2}$

We thank Dr P Yip, Department of Paediatrics, United Christian Hospital, for permission to report this patient, who was under her care. We are indebted to Mr HT Yeung and Mr Eric Ng, Diagnostic Laboratory, United Christian Hospital for technical help.

\section{References}

' Meleney FL. Hemolytic streptococcus gangrene. Arch Surg 1924;9:317-64.
2 Janevicius RV, Hann SE, Batt MD. Necrotising fasciitis (collective review). Surg Gynecol Obstet 1982;154:97-102.

${ }^{3}$ Leppard BJ, Seal DV. The value of bacteriology and serology in the diagnosis of necrotising fasciitis. $\mathrm{Br} J$ Dermatol 1983; 199:37-44.

4 Swartz MN. In: Mandell GL, Douglas RG, Bennett JE, eds. Principles and practice of infectious diseases. New York: Wiley Medical Publications, 1979:813-6.

${ }^{5}$ Giuliano A, Lewis F, Hadley K, Blaisdell FW. Bacteriology of necrotising fasciitis. Am J Surg 1977;134:52-7.

- Blake PA, Weaver RE, Hollis DG. Diseases of humans (other than cholera) caused by vibrios. Ann Rev Microbiol 1980;34:357-60.

7 Poole MD, Oliver JD. Experimental pathogenicity and mortality in ligated ileal loop studies of the newly reported halophilic lactose-positive vibrio sp. Infect Immun 1978;20:126-9.

- Weaver RE, Ehrenkranz NJ. Vibrio parahemolyticus septicaemia. Arch Intern Med 1975;135: 197.

9 Farmer JJ III. Vibrio ("Beneckea") vulnificus, the bacterium associated with sepsis, septicemia and the sea. Lancet 1979;ii: 903.

${ }^{10}$ Roland FP. Leg gangrene and endotoxin shock due to Vibrio parahemolyticus - an infection acquired in New England coastal waters. $N$ Engl J Med 1970;282:1306.

"Zide N, Davies J, Ehrenkranz NJ. Fulminating Vibrio parahemolyticus septicemia. Arch Intern Med 1974;133:479-81.

12 Thorsteinson SB, Minuth JN, Musher DM. Clinical manifestations of halophilic non-cholera vibrio infections. Lancet 1974;ii: $1283-4$.

${ }^{13}$ Fernandez CR, Pankey GA. Tissue invasion by unnamed marine vibrios. JAMA 1975;233:1173-6.

${ }^{14}$ Hollis DG, Weaver RE, Baker CN, Thornsberry C. Halophilic vibrio species isolated from blood cultures J Clin Microbiol 1976; 3:425-31.

is Matsuo T, Kohno S, Ikeda T, Saruwatari K, Nonomiya H. Fulminating lactose-positive vibrio septicemia. Acta Pathol Jap 1978; 28: 937-48.

${ }^{16}$ Blake PA, Merson MH, Weaver RE, et al. Disease caused by a marine vibrio (clinical characteristics and epidemiology). $N$ Engl J Med 1979;300:1-5.

17 Mertens A, Nagler J, Hansen W, Gepts-Friedenreich E. Halophilic lactose-positive vibrio in a case of fatal septicemia. J Clin Microbiol 1979;9:233-5.

${ }^{18}$ Tacket CO, Barrett TJ, Mann JM, Roberts MA, Blake PA. Wound infections caused by Vibrio vulnificus, a marine vibrio in inland areas of the United States. J Clin Microbiol 1984; 19: 197-9.

19 Castillo LE, Winslow DL, Pankey GA. Wound infection and septic shock due to Vibrio vulnificus. Am J Trop Med Hyg 1981;30:844-8.

${ }^{20}$ Kelly MT, McCormick WF. Acute bacterial myositis caused by Vibrio vulnificus. JAMA 1981;246:72-3.

Requests for reprints to: Professor GL French, University Department of Microbiology, 1/F, Clinical Sciences Building, Prince of Wales Hospital, Shatin, New Territories, Hong Kong. 